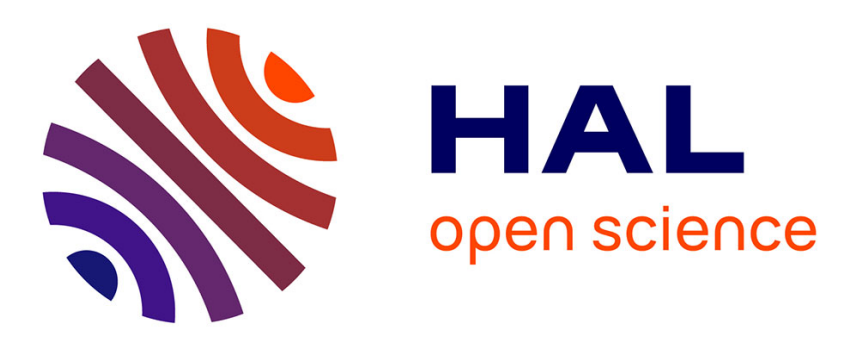

\title{
Effects of cold-rolling deformation on texture evolution and mechanical properties of Ti-29Nb-9Ta-10Zr alloy
}

\author{
V.-D. Cojocaru, D. Raducanu, Thierry Gloriant, D.M. Gordin, I. Cinca
}

\section{To cite this version:}

V.-D. Cojocaru, D. Raducanu, Thierry Gloriant, D.M. Gordin, I. Cinca. Effects of cold-rolling deformation on texture evolution and mechanical properties of Ti-29Nb-9Ta-10Zr alloy. Materials Science and Engineering: A, 2013, 586, pp.1-10. 10.1016/j.msea.2013.08.010 . hal-00865157

\section{HAL Id: hal-00865157 \\ https://hal.science/hal-00865157}

Submitted on 24 Sep 2013

HAL is a multi-disciplinary open access archive for the deposit and dissemination of scientific research documents, whether they are published or not. The documents may come from teaching and research institutions in France or abroad, or from public or private research centers.
L'archive ouverte pluridisciplinaire HAL, est destinée au dépôt et à la diffusion de documents scientifiques de niveau recherche, publiés ou non, émanant des établissements d'enseignement et de recherche français ou étrangers, des laboratoires publics ou privés. 


\title{
Effects of cold-rolling deformation on texture evolution and mechanical properties of Ti-29Nb-9Ta-10Zr alloy
}

\author{
V.D. Cojocaru ${ }^{\mathrm{a}}$, D. Raducanu ${ }^{\mathrm{a}}$, T. Gloriant ${ }^{\mathrm{b}}$, D.M. Gordin ${ }^{\mathrm{b}}$, I. Cinca $^{\mathrm{a}}$ \\ ${ }^{a}$ University Politehnica of Bucharest, Spl. Independentei 313, 060042 Bucharest, \\ Romania \\ ${ }^{\mathrm{b}}$ INSA Rennes, UMR CNRS 6226 SCR/Chimie-Métallurgie, F-35708 Rennes Cedex, \\ France
}

\begin{abstract}
The crystallographic texture of $\mathrm{Ti}-29 \mathrm{Nb}-9 \mathrm{Ta}-10 \mathrm{Zr}$ alloy is studied after cold-rolling with different amounts of thickness reduction, up to $60 \%$. The major texture components developed during cold-rolling were: $\gamma$-fibre components: $\{111\}\langle 1 \overline{1} 0\rangle,\{111\}\langle 0 \overline{1} 1\rangle$, $\{111\}\langle\overline{1} 1 \overline{1}\rangle$ and $\{111\}\langle\overline{1} \overline{1} 2\rangle$; texture component: $\{112\}\langle\overline{1} \overline{1} 1\rangle$ and texture components: $\{001\}\langle 0 \overline{1} 0\rangle$ and $\{010\}\langle 001\rangle$. Besides crystallographic texture the resulted mechanical properties were studied by nanoindentation. It was showed that the decrease in Young's modulus after different cold-rolling stages is mainly attributed to the stress-induced $\alpha$ "-Ti phase formation. At $60 \%$ cold-rolling thickness reduction obtained an elastic modulus close to $45.29 \pm 3.81 \mathrm{GPa}$, coupled with an average Vickers microhardness close to $279.83 \pm 4.28 \mathrm{HV}$.
\end{abstract}

\section{Keywords}

Titanium alloys; Cold deformation; Texture evolution; X-ray diffraction; Nanoindentation 


\section{Introduction}

Multicomponent Ti-alloys containing $\mathrm{Nb}$, Ta and $\mathrm{Zr}$ alloying elements, acting as $\beta$ stabilizers, have attracted much attention during the last decade, due to their good mechanical properties as well as high corrosion resistance and high biocompatibility. If mechanical properties are taken into consideration, i.e. Young elastic modulus, it was showed that the mechanical properties strongly depend on the alloy design and the thermo-mechanical processing parameters [1], [2] and [3]. The low elastic modulus multicomponent $\beta$-Ti alloys are commonly used in biomedical applications, i.e. as implants material [4], [5] and [6].

The use of Ti-alloys in biomedical applications needs to satisfy few demands referring to high biocompatibility, high corrosion resistance in body fluids and also to low elastic modulus, all being essential at the present day. The addition of $\mathrm{Nb}$, Ta and $\mathrm{Zr}$ non-toxic elements improve biocompatibility and also the corrosion resistance [7] and [8]. In order to surpass the "stress shielding effect" [9], which appears due to the large difference in alloys elastic modulus and bone elastic modulus (10-30 GPa), which can lead to bone resorption around the implant [10], the need of low elastic modulus alloys appeared. Low elastic modulus alloys (55$65 \mathrm{GPa})$ were obtained for different multicomponent $\mathrm{Ti}-\mathrm{Nb}-\mathrm{Ta}-\mathrm{Zr}$ alloys, such as: $\mathrm{Ti}-35 \mathrm{Nb}-$ 7Zr-5Ta (wt\%) [11] and [12], Ti-35Nb-2Ta-3Zr (wt\%) [13], Ti-29Nb-13Ta-4.6Zr (wt\%) and $\mathrm{Ti}-24 \mathrm{Nb}-4 \mathrm{Zr}-7.9 \mathrm{Sn}$ (wt\%) [14], [15] and [16].

Besides alloys composition design, the thermo-mechanical processing route is another way to obtain microstructures with low elastic modulus. In the case of Ti-alloys, it was proved that by obtaining a bimodal microstructure consisting of a parent $\beta$-Ti phase and a stress/thermal induced $\alpha^{\prime \prime}$-Ti phase, leads to a lower elastic modulus, due to the fact that $\alpha^{\prime \prime}$-Ti phase exhibits a lower elastic modulus comparing to parent $\beta$-Ti phase [17]. By manipulating the volume fraction of $\alpha^{\prime \prime}$-Ti phase it is possible to steer the elastic modulus towards desired values.

The purpose of the present study is to examine the effects of cold-rolling deformation on texture evolution and resulted mechanical properties for $\mathrm{Ti}-29 \mathrm{Nb}-9 \mathrm{Ta}-10 \mathrm{Zr}$ alloy, in order to gain more insight into the correlation between cold-rolling intensity, expressed by cold-rolled reduction, and resulted texture and mechanical properties.

\section{Material and methods}

\subsection{Thermo-mechanical processing route of $\mathrm{Ti}-29 \mathrm{Nb}-9 \mathrm{Ta}-10 \mathrm{Zr}$ alloy}

The investigated $\mathrm{Ti}-29 \mathrm{Nb}-9 \mathrm{Ta}-10 \mathrm{Zr}$ (wt \%) alloy was produced from commercially high purity elements by cold crucible induction in levitation melting, under argon protective atmosphere, using a FIVE CELES - MP25 furnace. Because of the large difference in melting temperature of component elements (Ti: $1660{ }^{\circ} \mathrm{C}$; $\mathrm{Nb}: 2468{ }^{\circ} \mathrm{C}$; $\mathrm{Ta}: 2996{ }^{\circ} \mathrm{C}$; $\mathrm{Zr}: 1855{ }^{\circ} \mathrm{C}$ ) and also in order to obtain a high degree of chemical homogeneity the obtained ingots were re-melted two times.

The Ti-29Nb-9Ta-10Zr alloy was thermo-mechanically (TM) processed (see Fig. 1) in order to obtain different structural states, exhibiting different texture characteristics and mechanical properties. 


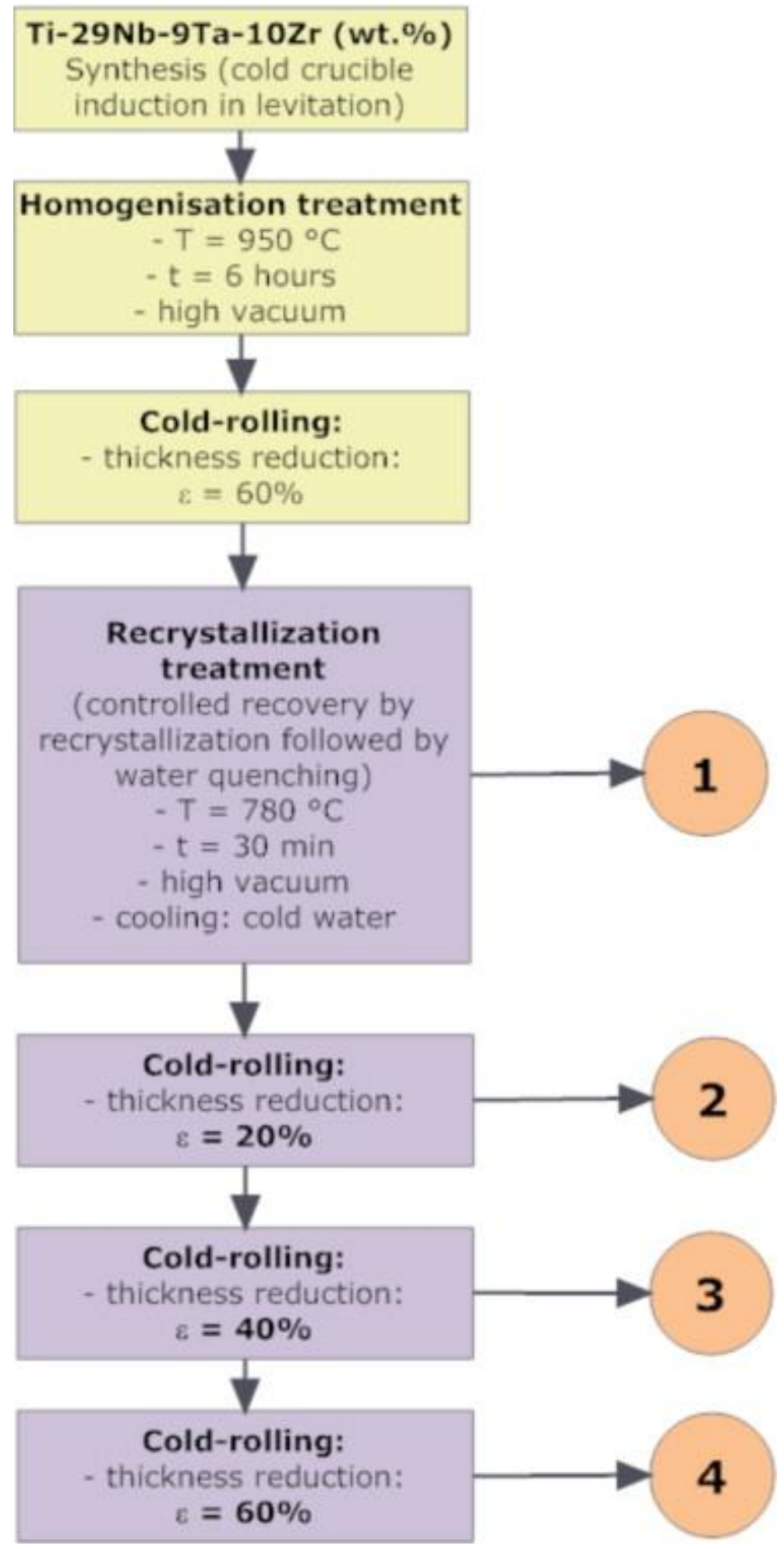

Fig. 1. Thermo-mechanical processing route applied on $\mathrm{Ti}-29 \mathrm{Nb}-9 \mathrm{Ta}-10 \mathrm{Zr}$ alloy.

After alloy synthesis, in order to increase the alloy homogeneity, a homogenization treatment was performed at $950{ }^{\circ} \mathrm{C}$ for $6 \mathrm{~h}$, in high vacuum. In order to obtain a refined structure, a first cold-rolling was applied using a thickness reduction of $60 \%$, followed by a recrystallization treatment, to remove the strain-hardening resulted during cold deformation. The recrystallization treatment was performed at $780{ }^{\circ} \mathrm{C}$ for $30 \mathrm{~min}$, in high vacuum. Recrystallized samples were water quenched in order to obtain a bimodal structure consisting 
of parent $\beta$-Ti phase and temperature-induced $\alpha^{\prime \prime}-\mathrm{Ti}$ phase. This structural state consisted as investigated state 1 (see Fig. 1).

The TM processing was continued by cold-rolling with different thickness reductions, resulting in investigated state 2 (20\% thickness reduction), investigated state 3 (40\% thickness reduction) and investigated state 4 (60\% thickness reduction).

All heat treatments (homogenization and recrystallization) were performed using a GERO SR $100 \times 500$ heat treatment oven. The cold-rolling deformation was performed using a Mario di Maio LQR120AS rolling-mill, at $3 \mathrm{~m} / \mathrm{min}$ rolling speed.

From all TM processed states, specimens were prepared and used in XRD, texture and nanoindentation measurements. All specimens were mounted in epoxy resin, grounded with 1200 grit $\mathrm{SiC}$ paper and mechanically polished using 6, 3,1 $\mu \mathrm{m}$ diamond paste and $0.03 \mu \mathrm{m}$ colloidal silica. Total removed thickness layer was about $150 \mu \mathrm{m}$. For all samples the observation plane was parallel to the plane formed by rolling-direction-transverse-direction (RD-TD plane).

\subsection{XRD measurements}

The XRD characterization was performed using a Philips PW 3710 diffractometer, with $\mathrm{Cu}$ $\mathrm{K}$-alpha $(\lambda=1.5406 \AA)$, in order to determine the phase structure and phase characteristics. The recorded XRD spectra's were simulated and fitted. The XRD spectra simulation was performed using MAUD v2.33 software package. In order to determine for each peak the position, intensity and peak broadening - FWHM (Full Width at Half Maximum) the XRD spectra's were fitted. The fitting procedure was performed using PeakFit v4.12 software package. A pseudo-Voigt diffraction line profile was used in fitting procedure.

\subsection{Texture analysis}

The texture characterization was performed using a Philips PW 3710 diffractometer, with $\mathrm{Cu}$ K-alpha ( $\lambda=1.5406 \AA$ ) wavelength. The (110), (200) and (211) Pole Figures (PF's) of the $\beta$-Ti phase were measured. The PF's were collected in $5^{\circ}$ increments: $0^{\circ}-\chi-85^{\circ}, 0^{\circ}-\phi-355^{\circ}$. The texture analysis was performed using MTEX v3.2.2 software package [18] and [19]. The PF's raw data was analyzed, using Gaussian distribution, Ghost correction and intensities normalization. Inverse Pole Figures (IPF's) and Orientation Distribution Functions (ODF's) were calculated.

Taking into consideration the low intensity of $\alpha^{\prime \prime}$-Ti peaks in comparison with $\beta$-Ti peaks, and the $\alpha^{\prime \prime}$-Ti peaks positions, closely situated to $\beta$-Ti peaks, makes the recording of $\alpha^{\prime \prime}$-Ti phase PF's difficult, for this reason only the texture of $\beta$-Ti phase is analyzed and presented here.

\subsection{Nanoindentation measurements}

Nanoindentation testing of $\mathrm{TM} \mathrm{Ti}-29 \mathrm{Nb}-9 \mathrm{Ta}-10 \mathrm{Zr}$ processed alloy was carried out using a CSM NHTX S/N: 01-03279 nanohardness tester under a constant load of $100 \mathrm{mN}$ and a loading/unloading rate of $200 \mathrm{mN} / \mathrm{min}$. The nanohardness tester was calibrated by using glass and fused silica samples. Using the initial gradient of the unloading curves the Instrumented 
Hardness (HIT) and Instrumented Elastic Modulus (EIT) were estimated using the Oliver and Pharr [20], [21] and [22] model. Vickers microhardness (HV) was determined also.

Ten measurements were made on each sample, the maxima and minima were removed and the rest were used in order to statistical analyze obtained parameters (HIT, EIT and HV).

\section{Results and discussion}

\subsection{XRD measurements}

Fig. 2 shows XRD spectra's of TM processed Ti-29Nb-9Ta-10Zr alloy. In the case of initial state (recrystallization+water quenching) (Fig. 1a) one can observe the presence of both $\beta$-Ti and $\alpha^{\prime \prime}$-Ti phases. The $\beta$-Ti phase shows presence of (110), (200) and (211) diffraction lines, while $\alpha^{\prime \prime}$-Ti phase shows presence of (020), (002), (200), (130), (022), (202) and (222) diffraction lines. The presence of $\alpha^{\prime \prime}$-Ti phase indicating the temperature-induced martensitic transformation $\beta \rightarrow \alpha^{\prime \prime}$ occurred during water quenching. The $\beta$-Ti phase was indexed in body centred cubic $(b c c)$ system - Im-3m, with a calculated lattice parameter of $a=3.30 \AA$, while $\alpha^{\prime \prime}$-Ti phase was indexed in orthorhombic system $-\mathrm{Cmcm}$, with calculated lattice parameters as it follows: $a=3.30 \AA ; b=4.77 \AA$ and $c=4.67 \AA$.
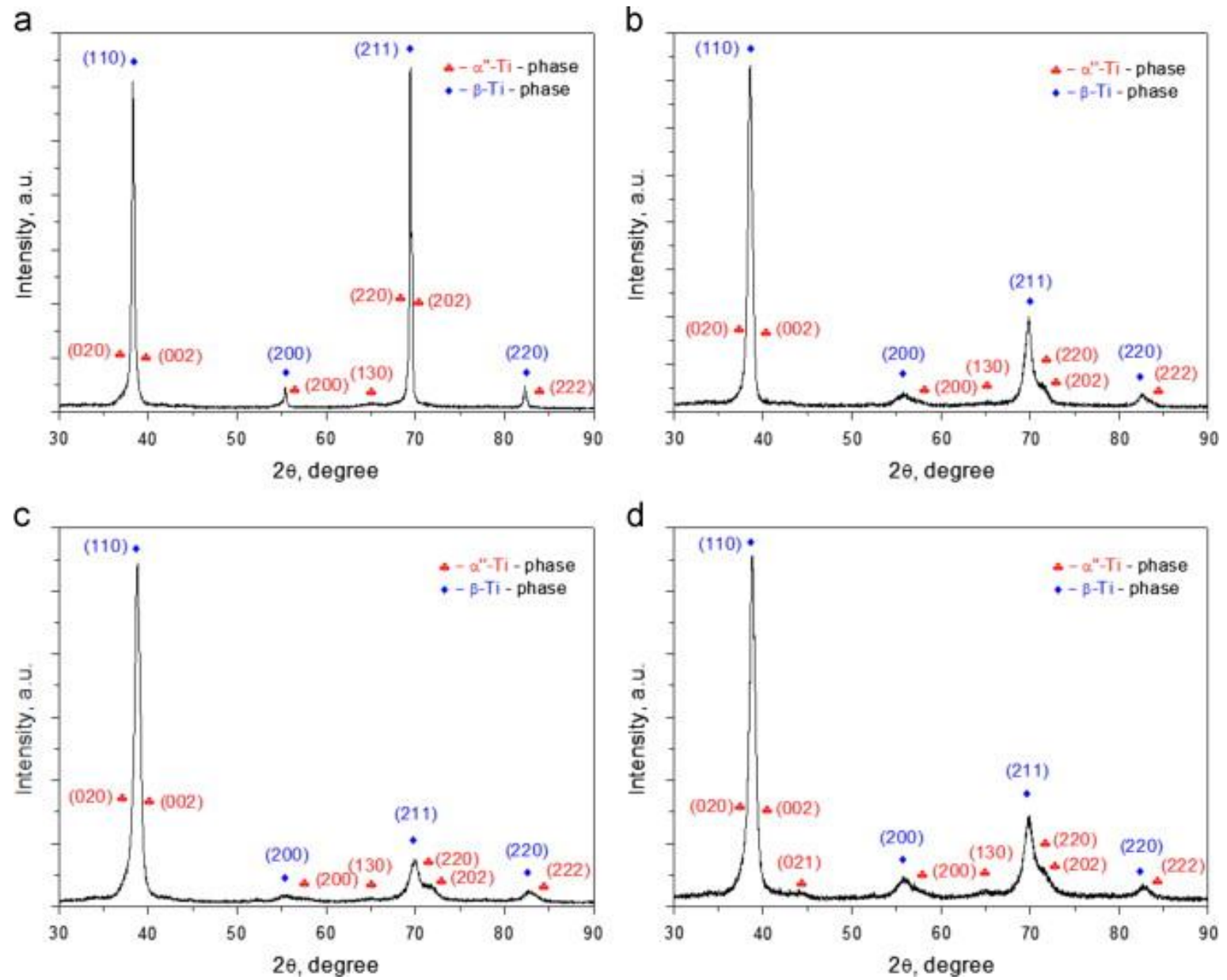

Fig. 2. XRD spectra's of TM processed Ti-29Nb-9Ta-10Zr alloy; a - Initial state; $b-$ $20 \%$ cold-rolled state; $c-40 \%$ cold-rolled state; $d-60 \%$ cold-rolled state. 
Fig. 3 shows detailed aspects corresponding to $2 \theta=\left(36^{\circ}-41^{\circ}\right)$ and $2 \theta=\left(67^{\circ}-74^{\circ}\right)$ XRD spectra of $20 \%$ cold-rolled state. One can observe the presence of both $\beta$-Ti and $\alpha^{\prime \prime}$-Ti peaks and also the resulted fitted data, as a convolution of constitutive $\beta$-Ti and $\alpha^{\prime \prime}-\mathrm{Ti}$ peaks. The fitted data accurately describe recorded XRD spectra. The $2 \theta=\left(36^{\circ}-41^{\circ}\right)$ spectra (Fig. 3a) shows the presence of (020) and (002) $\alpha^{\prime \prime}$-Ti and (110) $\beta$-Ti peaks, while the $2 \theta=\left(67^{\circ}-74^{\circ}\right)$ spectra (Fig. $3 \mathrm{~b})$ shows the presence of (220) and (202) $\alpha^{\prime \prime}$-Ti and (2 11 1) $\beta$-Ti peaks. Similar observations can be made in the case of all investigated states.
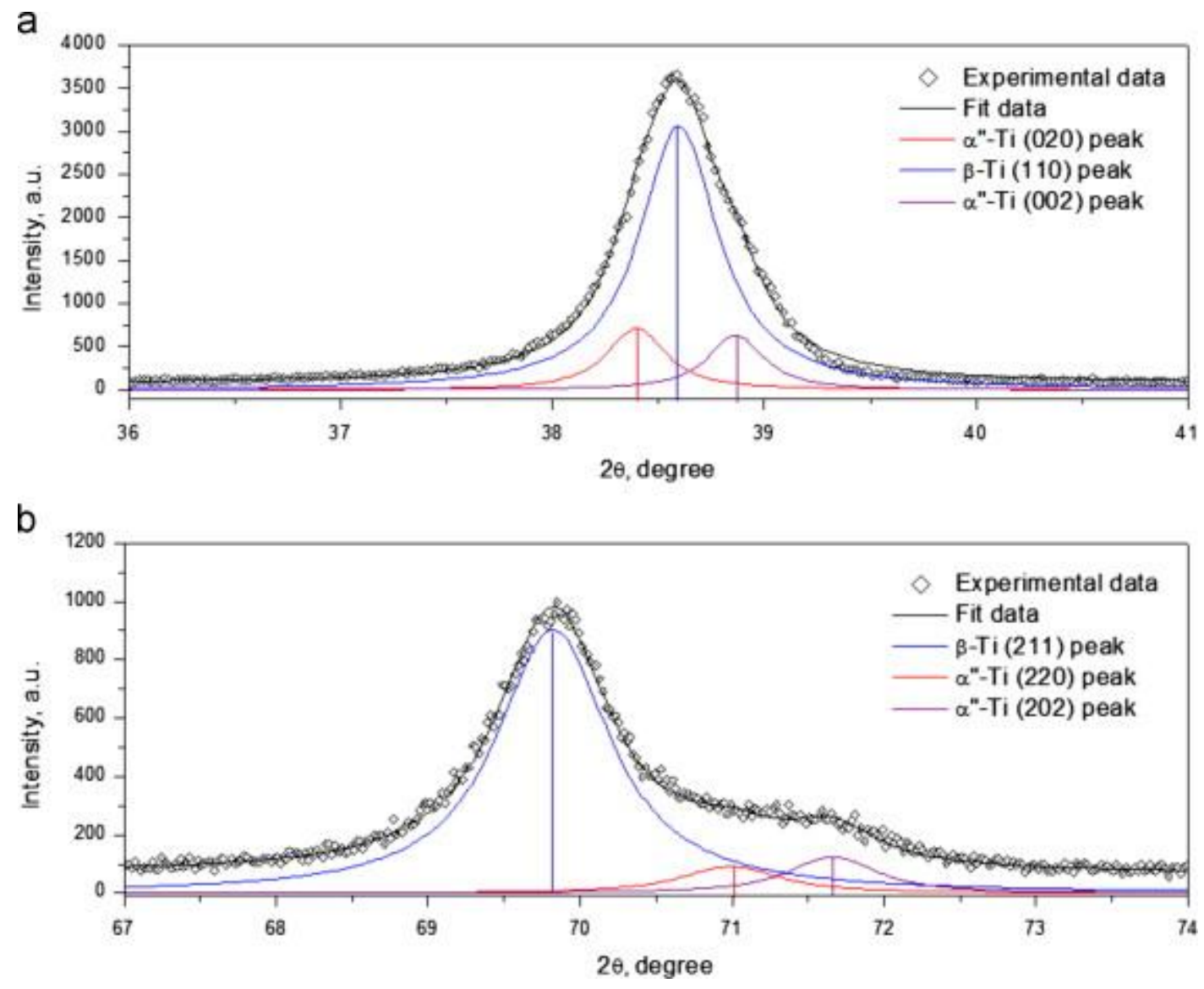

Fig. 3. Detailed XRD spectra corresponding to $2 \theta=\left(36^{\circ}-41^{\circ}\right)$ (a) and $2 \theta=\left(67^{\circ}-74^{\circ}\right)$ (b) of $20 \%$ cold-rolled $\mathrm{Ti}-29 \mathrm{Nb}-9 \mathrm{Ta}-10 \mathrm{Zr}$ alloy.

Analyzing the XRD spectra corresponding to $20 \%, 40 \%$ and $60 \%$ cold-rolled states (Fig. $2 \mathrm{~b}-$ d) it was found that the lattice parameter of $\beta$-Ti phase remains unchanged as $a=3.30 \AA$. Changes can be detected in lattice parameters of $\alpha^{\prime \prime}$-Ti phase, i.e. in the case of $20 \%$ coldrolled state calculated lattice parameters were $a=3.23 \AA ; b=4.72 \AA$ and $c=4.62 \AA$. Similar observations were reported in the case of TM processed Ti-22Nb-6Ta alloy [23], where the parent $\beta$-Ti phase showed a lattice parameter close to $a=3.289 \AA$ while lattice parameters of $\alpha^{\prime \prime}$-Ti phase were close to $a=3.221 \AA ; b=4.766 \AA$ and $c=4.631 \AA$. In the case of TM processed $\mathrm{Ti}-25 \mathrm{Nb}-25 \mathrm{Ta}$ alloy [24] (90\% cold-rolled) it was showed that the parent $\beta$-Ti phase showed a lattice parameter close to $a=3.28 \AA$ while lattice parameters of $\alpha^{\prime \prime}$-Ti phase were close to $a=3.21 \AA ; b=4.73 \AA$ and $c=4.63 \AA$.

In the case of $\alpha^{\prime \prime}-\mathrm{Ti}$ phase it can be noticed that the higher lattice change took place with respect to lattice parameter $a$, while smaller changes can be observed in the case of $b$ and $c$ lattice parameters (see Table 1). The presence of this change in $\alpha^{\prime \prime}$-Ti phase lattice parameters 
coupled with cold-deformation processing is indicating the $\beta \rightarrow \alpha^{\prime \prime}$ transformation during coldrolling occurs due to stress-induced martensitic transformation.

Table 1. Obtained $\beta$-Ti and $\alpha^{\prime \prime}$-Ti lattice parameters.

\begin{tabular}{|c|c|c|}
\hline \multirow{2}{*}{ Sample state } & \multirow{2}{*}{$\begin{array}{l}\beta \text {-Ti phase } \\
a(\AA)\end{array}$} & $\alpha^{\prime \prime}-7$ \\
\hline & & $a(\AA) b(\AA) c(\AA)$ \\
\hline Initial state & 3.30 & $3.30 \quad 4.77 \quad 4.67$ \\
\hline $20 \%$ cold-ro & 3.30 & $3.23 \quad 4.72 \quad 4.62$ \\
\hline $40 \% \mathrm{c}$ & 30 & $3.23 \quad 4.72 \quad 4.62$ \\
\hline $0 \%$ cold-rol & 3.30 & $3.21 \quad 4.70 \quad 4.60$ \\
\hline
\end{tabular}

Almost identical lattice parameters were obtained in the case of $40 \%$ cold-rolled state in comparison with $20 \%$ cold-rolled state. A difference appears for $60 \%$ cold-rolled state, when calculated lattice parameters were $a=3.21 \AA ; b=4.70 \AA$ and $c=4.60 \AA$.

Comparing the intensity of $\alpha^{\prime \prime}$-Ti phase peaks corresponding to $20 \%, 40 \%$ and $60 \%$ coldrolling states, an increase in $\alpha^{\prime \prime}$-Ti phase peaks intensity can be observed, due to fact that the stress-induced martensitic transformation progresses with increasing of cold deformation (increasing the volume fraction of $\alpha^{\prime \prime}$-Ti phase). At $60 \%$ cold-rolling reduction the stressinduced martensitic transformation is still not suppressed by this large deformation, this suggest that the volume fraction of $\alpha^{\prime \prime}-\mathrm{Ti}$ phase can still be increased by further cold-rolling deformation. The $\alpha^{\prime \prime}$-Ti phase peaks broadening (FWHM parameter) increases with the increase of cold deformation, suggesting a continuous decrease in grain-size of $\alpha^{\prime \prime}$-Ti phase, due to a combination of increasing grain refinement and internal stress caused by the cold deformation [13] and [17].

\subsection{Texture analysis}

Crystallographic texture features of the $\beta$-Ti phase in the TM processed $\mathrm{Ti}-29 \mathrm{Nb}-9 \mathrm{Ta}-10 \mathrm{Nb}$ alloy is analyzed and presented here.

In order to determine the complete texture features, the Inverse Pole Figures (IP's) and Orientation Distribution Functions (ODF's) must be obtained. In the case of many important engineering materials the properties are strongly direction-dependent.

The IPF shows how the selected direction in the sample reference frame is distributed in the reference frame of the crystal. Fig. 4 shows the distribution of rolling direction (RD), transverse direction (TD) and normal direction (ND) with respect to reference frame of the crystal, in the case of $\mathrm{TM}$ processed $\mathrm{Ti}-29 \mathrm{Nb}-9 \mathrm{Ta}-10 \mathrm{Nb}$ alloy. 

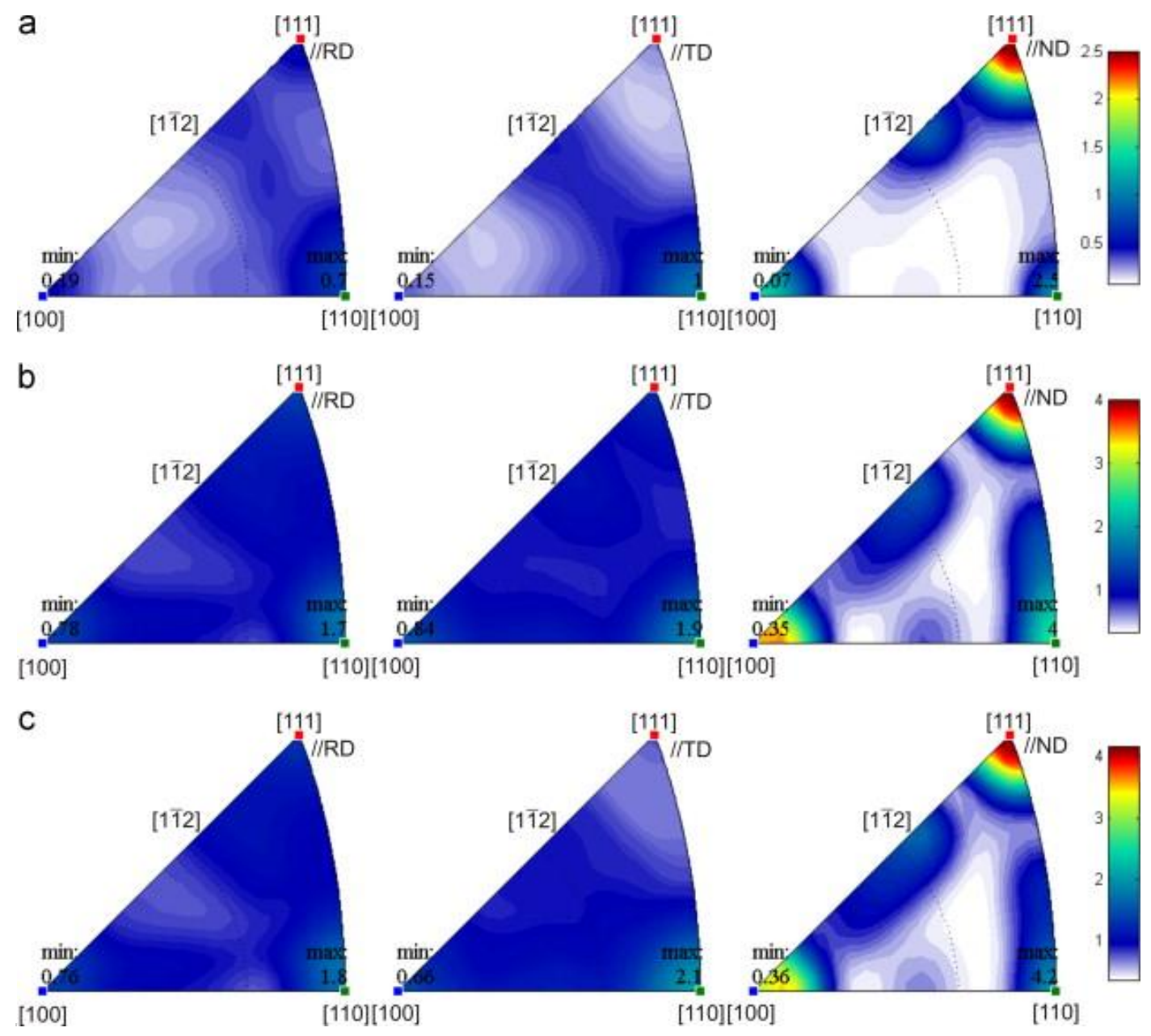

Fig. 4. Representation of Inverse Pole Figures (IPF's) corresponding to TM processed Ti-29Nb-9Ta-10Zr alloy; a - 20\% cold-rolled state; b - 40\% cold-rolled state; c $60 \%$ cold-rolled state.

In the case of $20 \%$ cold-rolled state (see Fig. 4a) one can observe that [111] crystallographic direction is most likely parallel to sample normal direction (ND), the [111]//ND pair reaching an intensity close to 2.5 . In the case of RD and TD directions most intense observed pairs are $[110] / / \mathrm{RD}$ and $[110] / / \mathrm{TD}$, with an intensity of 0.7 and respectively 1.0. Same observation can be made in the case of $40 \%$ cold-rolled state (see Fig. $4 \mathrm{~b}$ ) and $60 \%$ cold-rolled state (see Fig. $4 \mathrm{c})$, with the difference that the observed pairs intensity is increasing. The maximum intensity is obtained in the case of [111]//ND pair, reaching an intensity close to 4.2 in the case of $60 \%$ cold-rolling state.

This increase in observed pairs intensity can be attributed to the increased number of grains resulted during cold-rolling grain refining process and also to the grain rotations resulted during deformation.

In order to calculate the ODFs, few assumptions were made, first, sample crystalline symmetry was indexed in cubic Im-3m system, and second, sample geometric symmetry was indexed in orthorhombic $\mathrm{mmm}$ system. 
The crystallographic texture is typically represented in the reduced Euler space using the Bunge system $\left(\varphi_{1}-\Phi-\varphi_{2}\right)$. In the case of $b c c$ metals the most important developed texture fibres are [25], [26] and [27]:

- $\alpha$-fibre (crystallographic fibre axis $\langle 110\rangle$ parallel to the rolling direction, including major components: $\{001\}\langle 110\rangle ;\{112\}\langle 110\rangle ;\{111\}\langle 110\rangle)$;

- $\gamma$-fibre (crystallographic fibre axis $\langle 111\rangle$ parallel to the normal direction, including major components: $\{110\}\langle 110\rangle ;\{111\}\langle 112\rangle)$;

- $\eta$-fibre (crystallographic fibre axis $\langle 001\rangle$ parallel to the rolling direction, including major components: $\{001\}\langle 100\rangle ;\{011\}\langle 100\rangle)$;

- $\zeta$-fibre (crystallographic fibre axis $\langle 011\rangle$ parallel to the normal direction, including major components: $\{011\}\langle 100\rangle ;\{011\}\langle 211\rangle ;\{011\}\langle 111\rangle ;\{011\}\langle 011\rangle)$;

- $\varepsilon$-fibre (crystallographic fibre axis $\langle 011\rangle$ parallel to the transversal direction, including major components: $\{001\}\langle 011\rangle ;\{112\}\langle 111\rangle ;\{111\}\langle 112\rangle ;\{011\}$ $\langle 100\rangle)$;

- $\theta$-fibre (crystallographic fibre axis $\langle 001\rangle$ parallel to the normal direction, including major components: $\{001\}\langle 100\rangle)$.

Usually, using the Bunge system $\left(\varphi_{1}-\Phi-\varphi_{2}\right)$, the ODF's are represented in $\varphi_{2}$ sections. The most relevant ODF's sections, in the case of $b c c$ metals, corresponds to $\varphi_{2}=0^{\circ}$ and $\varphi_{2}=45^{\circ}$ sections [24].

Fig. 5 shows the ODF's sections corresponding to $\varphi_{2}=0^{\circ}$ (Fig. 5a) and $\varphi_{2}=45^{\circ}$ (Fig. 5 b) of the $20 \%$ cold-rolled state. The highest orientation densities are obtained in the case of $\varphi_{2}=45^{\circ}$ section, with a maximum of orientation density close to 3.1 corresponding to $\{111\}\langle 1 \overline{1} 0\rangle$ and $\{111\}\langle 0 \overline{1} 1\rangle$ texture components, both being invariants of $\{111\}\langle 110\rangle$ system and belonging to $\gamma$-fibre, while an orientation density between 2.4 and 2.6 is observed in the case of $\{111\}\langle\overline{12} 1\rangle$ and $\{111\}\langle\overline{1} \overline{1} 2\rangle$ texture components, both being invariants of $\{111\}$ 112 system and belonging to $\gamma$-fibre. Smaller orientation density, between 1.8 and 2.0, are observed in the case of $\{112\}\langle\bar{T} \overline{1} 1\rangle,\{001\}\langle 1 \overline{1} 0\rangle$ and $\{001\}\langle\overline{1} \overline{1} 0\rangle$ texture components. 

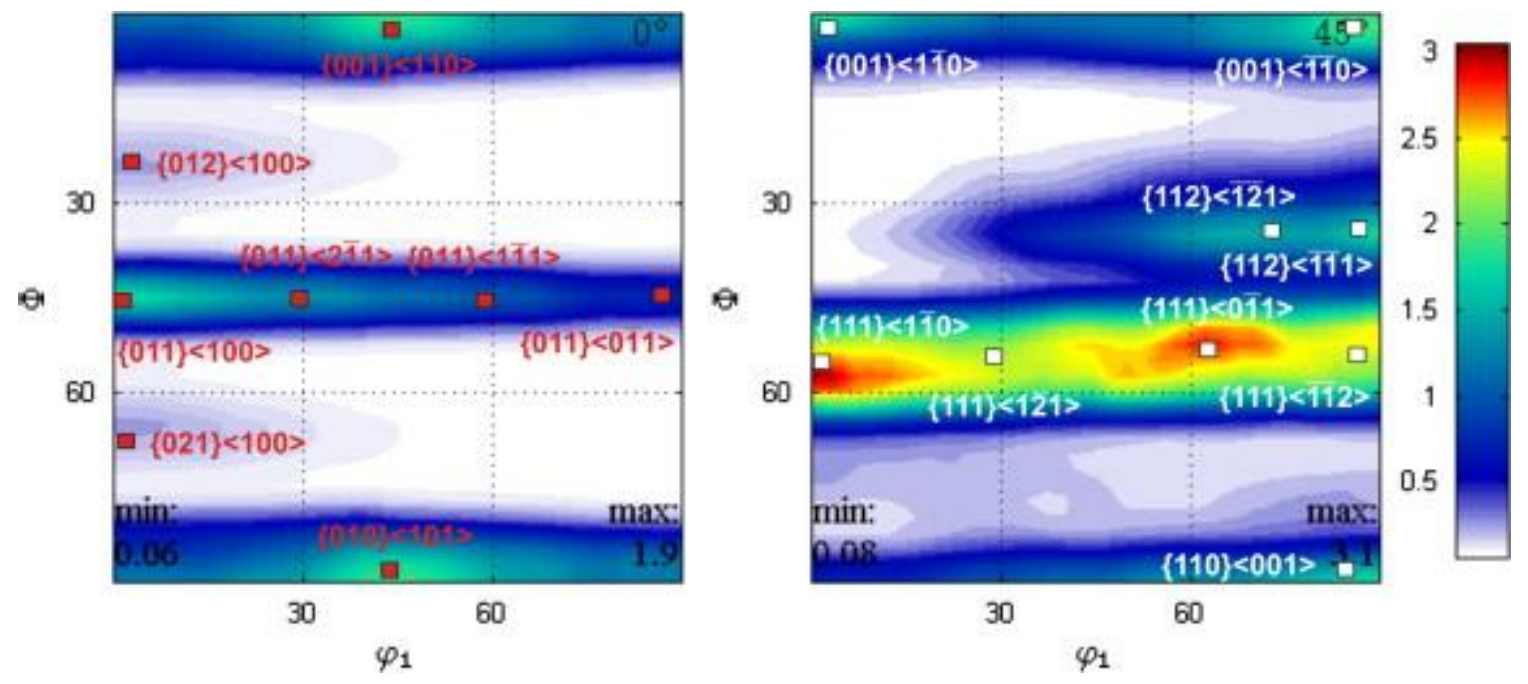

Fig. 5. Representation of Orientation Distribution Functions (ODF's) corresponding to $20 \%$ cold-rolled $\mathrm{Ti}-29 \mathrm{Nb}-9 \mathrm{Ta}-10 \mathrm{Zr}$ alloy; $\mathrm{a}-\mathrm{ODF}$ section: $\varphi_{2}=0^{\circ} ; \mathrm{b}-\mathrm{ODF}$ section: $\varphi_{2}=45^{\circ}$.

Comparing the $40 \%$ cold-rolled (Fig. 6) state with $20 \%$ cold-rolled state an important increase in orientation density of $\{112\}\langle\bar{T} \overline{1} 1\rangle$ texture component from 1.8 to respectively 4.1 can be observed, becoming a major texture component (Fig. 6b). A smaller increase is observed in the case of $\{111\}\langle 1 \overline{1} 0\rangle$ and $\{111\}\langle\overline{0} 1\rangle$ texture components, from 3.1 to respectively 4.1. It must be noticed that the orientation density of $\{001\}\langle 0 \overline{1} 0\rangle$ and $\{010\}\langle 001\rangle$ texture components, both being invariants of $\{001\}\langle 100\rangle$ system, show dramatic increase to almost 3.5 (Fig. 6a).
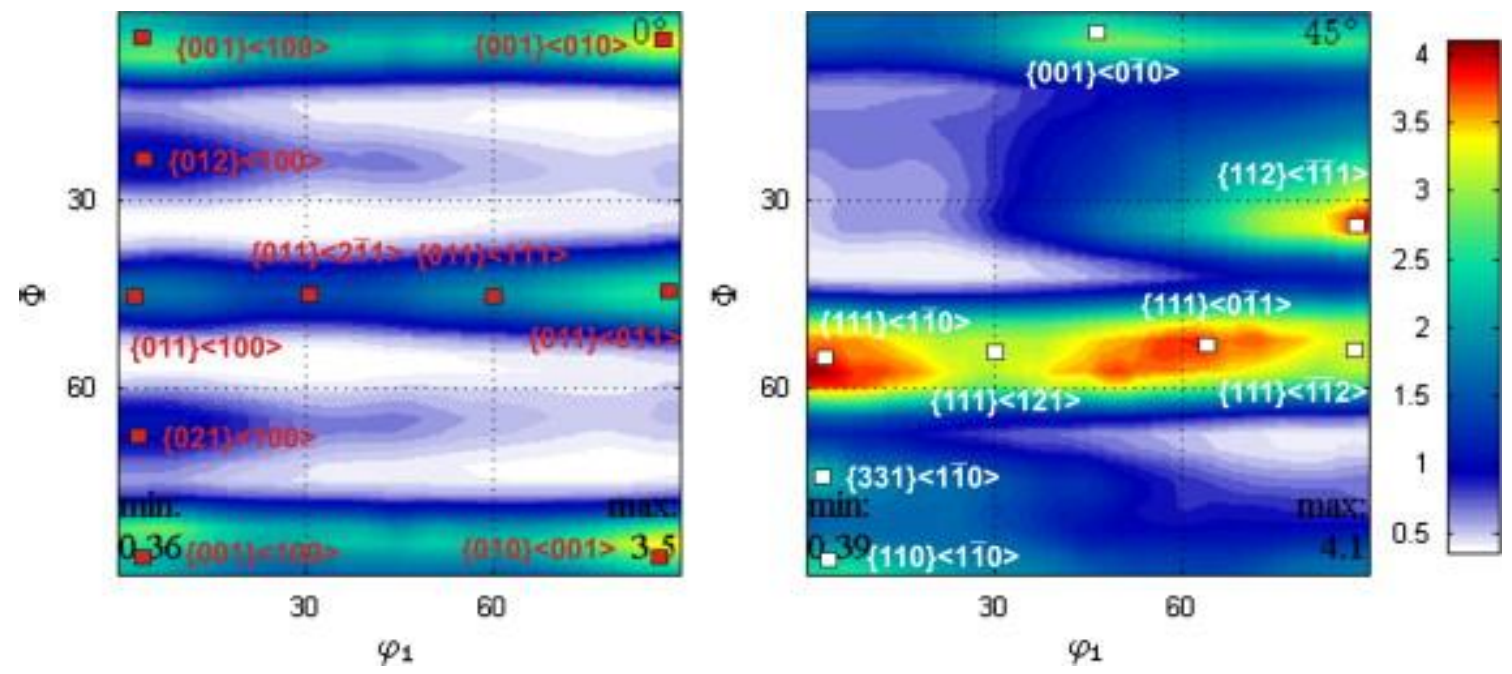

Fig. 6. Representation of Orientation Distribution Functions (ODF's) corresponding to $40 \%$ cold-rolled Ti-29Nb-9Ta-10Zr alloy; a - ODF section: $\varphi_{2}=0^{\circ} ; \mathrm{b}-$ ODF section: $\varphi_{2}=45^{\circ}$.

In the case of $60 \%$ cold-rolled state (Fig. 7) it can be observed that the orientation density of $\{001\}\langle 0 \overline{1} 0\rangle$ and $\{010\}\langle 001\rangle$ texture components increases to a maximum value of about 4.3, becoming a major texture component (Fig. 7a). The orientation density of $\gamma$-fibre texture components, expressed by $\{111\}\langle 1 \overline{1} 0\rangle,\{111\}\langle\overline{0} \overline{1} 1\rangle,\{111\}\langle 1 \overline{2} 1\rangle$ and $\{111\}\langle$ 
$\overline{1} \overline{1} 2\rangle$ texture components, increase to 4.2 in the case of $\{111\}\langle 110\rangle$ invariants and respectively to 4.1 in the case of $\{111\}\langle 112\rangle$ invariants (Fig. 7b). Also, the orientation density of $\{001\}\langle\overline{1} \overline{1} 0\rangle$ texture component increase to 4.1 , becoming a major texture component.
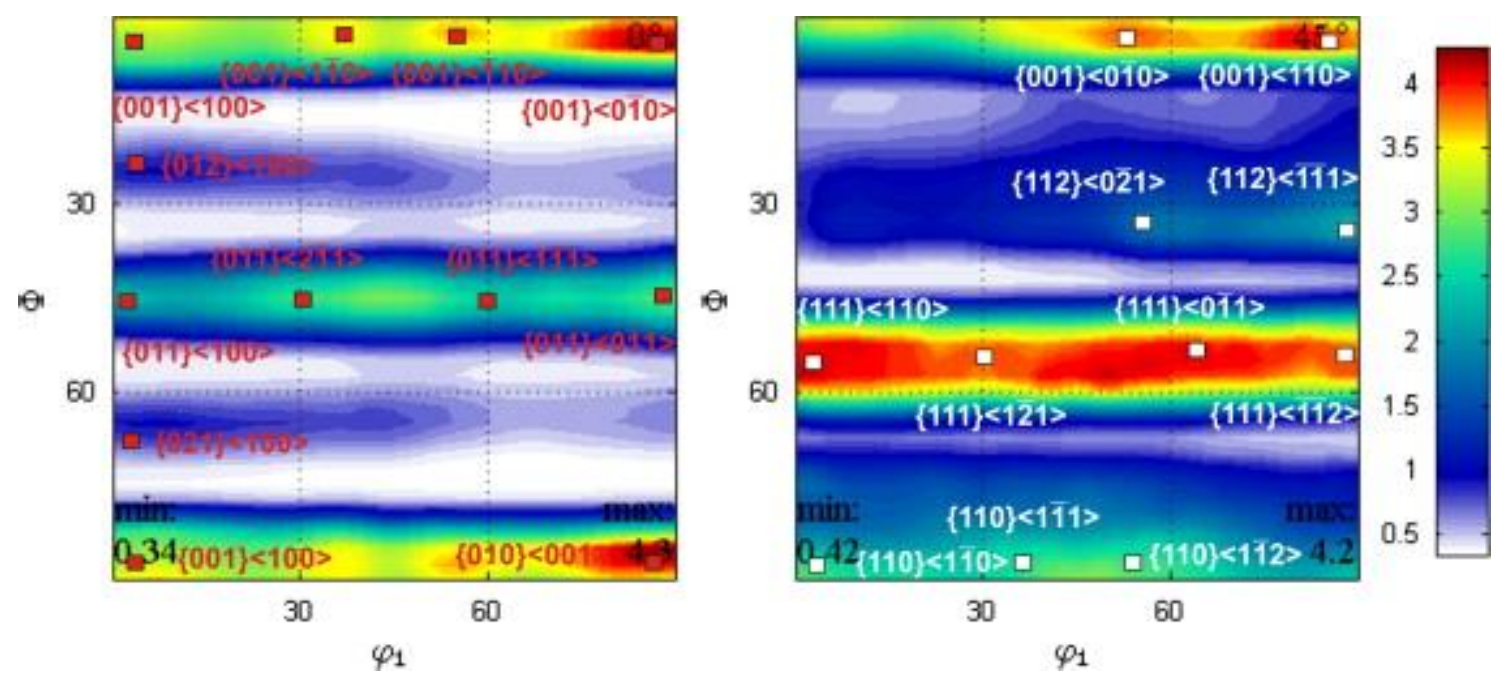

Fig. 7. Representation of Orientation Distribution Functions (ODF's) corresponding to $60 \%$ cold-rolled Ti-29Nb-9Ta-10Zr alloy; a - ODF section: $\varphi_{2}=0^{\circ} ; \mathrm{b}-$ ODF section: $\varphi_{2}=45^{\circ}$.

The $\{001\}\langle 110\rangle$ texture component, with $\{001\}\langle 1 \overline{1} 0\rangle$ and $\{001\}\langle\overline{1} \overline{1} 0\rangle$ invariants, is commonly observed in $b c c \beta$-Ti alloys after cold-rolling [23], [24], [28] and [29]. It was reported in the case of $\mathrm{Ti}-35 \mathrm{Nb}-7 \mathrm{Zr}-5 \mathrm{Ta}$ [27] and $\mathrm{Ti}-25 \mathrm{Nb}-10 \mathrm{Ta}-1 \mathrm{Zr}-0.2 \mathrm{Fe}$ [17] that the $\gamma-$ fibre expressed by $\{001\}\langle 110\rangle$ texture component, spreading from $\{111\}\langle 1 \overline{1} 0\rangle$ to $\{111\}$ $\langle 0 \overline{1} 1\rangle$, and by $\{111\}\langle 112\rangle$ texture component, spreading from $\{111\}\langle\overline{1} 1\rangle$ to $\{111\}$ $\langle\overline{1} \overline{1} 2\rangle$, is the most important developed texture component after cold-rolling with $70 \%$ thickness reduction.

Based on ODF's data, calculations of textured volume with a certain modal orientation, as well as texture index are possible. In order to calculate the textured volume with a certain modal orientation it was assumed that the misorientation tolerance was $15^{\circ}$.

In the case of $20 \%, 40 \%$ and $60 \%$ cold-rolled states, data concerning calculated texture volumes of major observed texture components as well as calculated texture index, are presented in Table 2. If considering the texture index, it must be noticed that it is increasing with increase in the applied thickness reduction, from 1.244 corresponding to $20 \%$ coldrolling, to 1.461 corresponding to $40 \%$ cold-rolling and finally to 1.538 corresponding to $60 \%$ cold-rolling. 
Table 2. Obtained texture characteristics for $\mathrm{TM}$ processed $\mathrm{Ti}-29 \mathrm{Nb}-9 \mathrm{Ta}-10 \mathrm{Zr}$ alloy.

\begin{tabular}{|c|c|c|c|c|c|c|}
\hline \multirow{2}{*}{$\begin{array}{l}\text { Sample } \\
\text { state }\end{array}$} & \multicolumn{3}{|c|}{$\begin{array}{l}\text { Modal orientation } \\
\text { (MO) }\end{array}$} & \multirow{2}{*}{$\begin{array}{l}\text { Texture component } \\
\{h k l\}\langle u v w\rangle\end{array}$} & \multirow{2}{*}{$\begin{array}{l}\text { Textured } \\
\text { with same }\end{array}$} & \multirow{2}{*}{$\begin{array}{l}\text { volume Texture } \\
\text { MO }(\%) \text { index }\end{array}$} \\
\hline & $\begin{array}{l}\varphi_{1} \\
\text { (deg) }\end{array}$ & $\begin{array}{l}\Phi \\
\text { (deg) }\end{array}$ & $\begin{array}{l}\varphi_{2} \\
(\mathrm{deg})\end{array}$ & & & \\
\hline \multirow{9}{*}{$\begin{array}{l}20 \% \text { cold- } \\
\text { rolled }\end{array}$} & 90 & 0 & 0 & $\{001\}\langle 0 \overline{1} 0\rangle$ & \multirow{9}{*}{\multicolumn{2}{|c|}{1.244}} \\
\hline & 90 & 90 & 0 & $\{010\}\langle 001\rangle$ & & \\
\hline & 0 & 45 & 0 & $\{011\}\langle 100\rangle$ & & \\
\hline & 90 & 45 & 0 & $\{011\}\langle 1 \overline{1} 0\rangle$ & & \\
\hline & 90 & 0 & 45 & $\{001\}\langle\overline{1} \overline{1} 0\rangle$ & & \\
\hline & 90 & 30 & 45 & $\{112\}\langle\overline{1} \overline{1} 1\rangle$ & & \\
\hline & 0 & 55 & 45 & $\{111\}\langle 1 \overline{1} 0\rangle$ & & \\
\hline & 30 & 55 & 45 & $\{111\}\langle 1 \overline{2} 1\rangle$ & & \\
\hline & 60 & 55 & 45 & $\{111\}\langle\overline{0} \overline{1}\rangle$ & & \\
\hline \multirow{11}{*}{$\begin{array}{l}40 \% \text { cold- } \\
\text { rolled }\end{array}$} & 90 & 55 & 45 & $\{111\}\langle\overline{1} \overline{1} 2\rangle$ & \multirow{11}{*}{\multicolumn{2}{|c|}{1.461}} \\
\hline & 90 & 0 & 0 & $\{001\}\langle 0 \overline{1} 0\rangle$ & & \\
\hline & 90 & 90 & 0 & $\{010\}\langle 001\rangle$ & & \\
\hline & 0 & 45 & 0 & $\{011\}\langle 100\rangle$ & & \\
\hline & 90 & 45 & 0 & $\{011\}\langle 1 \overline{1} 0\rangle$ & & \\
\hline & 90 & 0 & 45 & $\{001\}\langle\overline{1} \overline{1} 0\rangle$ & & \\
\hline & 90 & 30 & 45 & $\{112\}\langle\overline{1} \overline{1} 1\rangle$ & & \\
\hline & 0 & 55 & 45 & $\{111\}\langle 1 \overline{1} 0\rangle$ & & \\
\hline & 30 & 55 & 45 & $\{111\}\langle 1 \overline{2} 1\rangle$ & & \\
\hline & 60 & 55 & 45 & $\{111\}\langle\overline{0} \overline{1} 1\rangle$ & & \\
\hline & 90 & 55 & 45 & $\{111\}\langle\overline{1} \overline{1} 2\rangle$ & & \\
\hline \multirow{10}{*}{$\begin{array}{l}60 \% \text { cold- } \\
\text { rolled }\end{array}$} & 90 & 0 & 0 & $\{001\}\langle 0 \overline{1} 0\rangle$ & \multirow{10}{*}{\multicolumn{2}{|c|}{1.538}} \\
\hline & 90 & 90 & 0 & $\{010\}\langle 001\rangle$ & & \\
\hline & 0 & 45 & 0 & $\{011\}\langle 100\rangle$ & & \\
\hline & 90 & 45 & 0 & $\{011\}\langle 1 \overline{1} 0\rangle$ & & \\
\hline & 90 & 0 & 45 & $\{001\}\langle\overline{1} \overline{1} 0\rangle$ & & \\
\hline & 90 & 30 & 45 & $\{112\}\langle\overline{1} \overline{1} 1\rangle$ & & \\
\hline & 0 & 55 & 45 & $\{111\}\langle 1 \overline{1} 0\rangle$ & & \\
\hline & 30 & 55 & 45 & $\{111\}\langle 1 \overline{2} 1\rangle$ & & \\
\hline & 60 & 55 & 45 & $\{111\}\langle\overline{0 \top} 1\rangle$ & & \\
\hline & 90 & 55 & 45 & $\{111\}\langle\overline{1} \overline{1} 2\rangle$ & 7.75 & \\
\hline
\end{tabular}


Iff considering the most intense observed texture components, the $\{111\}\langle 1 \overline{1} 0\rangle$ and $\{111\}$ \rangle invariants, which show a textured volume of about $5.28 \%$ and respectively $5.31 \%$ in the case of $20 \%$ cold-rolled state, an increase in textured volume up to $8.11 \%$ and respectively $8.31 \%$ corresponding to $40 \%$ cold-rolled state can be observed. A further increase of coldrolling reduction to $60 \%$ has as effect a smaller increase in textured volume, up to $894 \%$ and respectiv $\bar{\Phi} \overline{1} 28.86 \%$. A similar behaviour can be identified in the case of $\{111\}\langle\rangle$ and $\{111\}\langle\rangle$ invariants. It must be noticed that the increase of textured volume is almost linear up to $60 \%$ thickness reduction, from $2.98 \%$ and respectively $3.17 \%$, in the case of $20 \%$ cold-rolled state, to $5.63 \%$ and respectively $5.51 \%$ in the case of $40 \%$ cold-rolled state and finally to $7.84 \%$ and respectively $7.75 \%$ in the case of $60 \%$ cold-rolled state.

If we take into consideration the $\{001\}\langle 0 \overline{1} 0\rangle$ texture component, a continuous increase in textured volume can be observed, from $1.11 \%$ corresponding to $20 \%$ cold-rolled state, to $4.15 \%$ corresponding to $40 \%$ cold-rolled state and finally to $5.36 \%$ corresponding to $60 \%$ cold-rolled state. The higher increase rate is noticed for a thickness reduction between $20 \%$ and $40 \%$.

Another noticeable behaviour is observed in the case of $\{112\}\langle\overline{1} \overline{1} 1\rangle$ texture component, a thickness reduction of $20 \%$ leads to a textured volume in $\{112\}\langle\overline{1} \overline{1} 1\rangle$ system of about $2.18 \%$, increasing the thickness reduction to $40 \%$ an increase up to $8.11 \%$ is observed, a further increase in thickness reduction up to $60 \%$ leads to a drastic decrease up to $1.97 \%$.

This type of variation in the case of textured volume with same modal orientation can be explained by the differences in activation mechanism of each texture component. During plastic deformation, as a consequence of the shear on specific favourable oriented crystal planes and directions the grains deform due to slip and/or twinning. The number of active slip/twinning systems is affected by the applied strain and constraints between neighbouring grains. Slip/twinning activation and their variation within and between grains determine the deformation microstructure and the change of grains orientation. During cold-rolling, the slip/twinning planes rotate due to dislocation glide, the rotation being towards the tensile axis, as a consequence of constraint of the axis. Slip/twinning planes rotation make possible the activation of different $\{h k l\}\langle u v w\rangle$ texture components [30].

A way to explain how a texture component can be activated during deformation can be made using the Schmid factor (SF) analysis. If considered a $\{h k l\}$ slip plane and an orthogonal slip direction $\langle u v w\rangle$ to the slip plane and assuming a simple shear in $\langle 101\rangle$ direction then computation of the SF associated to $\{h k l\}\langle u v w\rangle$ slip system is possible. Same computation can be made in the case of $\{h k l\}\langle u v w\rangle$ twinning systems [31]. The Schmid factor (SF) can be defined as

$S F=\cos \lambda \cdot \cos \phi$

where $\lambda$ is the angle between the simple shear direction and normal to the slip/twinning plane and $\phi$ is the angle between the simple shear direction slip/twinning direction. The $\lambda$ and $\phi$ angles can take values between $0^{\circ}$ and $180^{\circ}$.

Computed valued of SF's associated to major observed texture components are presented in Table 3. As observed, firstly activated deformation mechanisms consist in slip deformation followed by twinning. Associating data concerning SF's values of activated slip/twinning 
systems with intensity of deformation, expressed by thickness reduction, leads to assumption that in early stages of deformation, up to $20 \%$ thickness reduction, only slip systems are activated, mainly $\{111\}\langle 1 \overline{1} 0\rangle$ and $\{111\}\langle 0 \overline{1} 1\rangle$ systems. Increasing the intensity of deformation, up to $40 \%$ thickness reduction, the $\{001\}\langle 0 \overline{1} 0\rangle$ slip system becomes active. Besides slip deformation, twinning deformation appears, the $\{112\}\langle\overline{1} \overline{1} 1\rangle$ twinning system being activated. Further increasing the intensity of deformation, up to $60 \%$ thickness reduction, the $\{111\}\langle 1 \overline{1} 0\rangle,\{111\}\langle 0 \overline{1} 1\rangle$ and $\{001\}\langle 0 \overline{1} 0\rangle$ slip systems remain active but the $\{112\}\langle\overline{1} \overline{1} 1\rangle$ twinning system is replaced by the $\{111\}\langle 1 \overline{2} 1\rangle$ and $\{111\}\langle\overline{1} \overline{1} 2\rangle$ systems.

Table 3. Obtained SF's for observed slip/twinning systems.

\begin{tabular}{|c|c|c|}
\hline No. Slip systems $\{h k l\}\langle u v t\rangle$ & Twinning systems $\{h k l\}\langle u v t\rangle$ & Schmid factor $|\mathbf{S F}|$ \\
\hline $1 \quad\{001\}\langle 0 \bar{T} 0\rangle$ & - & 0.394 \\
\hline $2-$ & $\{112\}\langle\overline{1} \overline{1} 1\rangle$ & 0.358 \\
\hline $3 \quad\{111\}\langle 1 \overline{1} 0\rangle$ & - & 0.408 \\
\hline $4 \quad\{111\}\langle\overline{0 \top} 1\rangle$ & - & 0.408 \\
\hline $5-$ & $\{111\}\langle 1 \overline{2} 1\rangle$ & 0.358 \\
\hline $6-$ & $\{111\}\langle\overline{1} \overline{1} 2\rangle$ & 0.358 \\
\hline
\end{tabular}

\subsection{Nanoindentation measurements}

Using nanoindentation is possible to determine a material hardness by knowing the geometry and indentation depth of the used indenter, through indirect measurement of the contact area at maximum applied load. Hardness is obtained by dividing the maximum applied load to contact area at maximum applied load. The Instrumented Elastic Modulus (EIT) (Young's modulus) can be determined from the initial slop of the unloading curve. If using the depth sensing instrumented indentation technique, hardness and elastic modulus can be determined using the Oliver and Pharr model [20], [21] and [22]. A typical nanoindentation loadindentation depth curve is presented in Fig. 8a. 

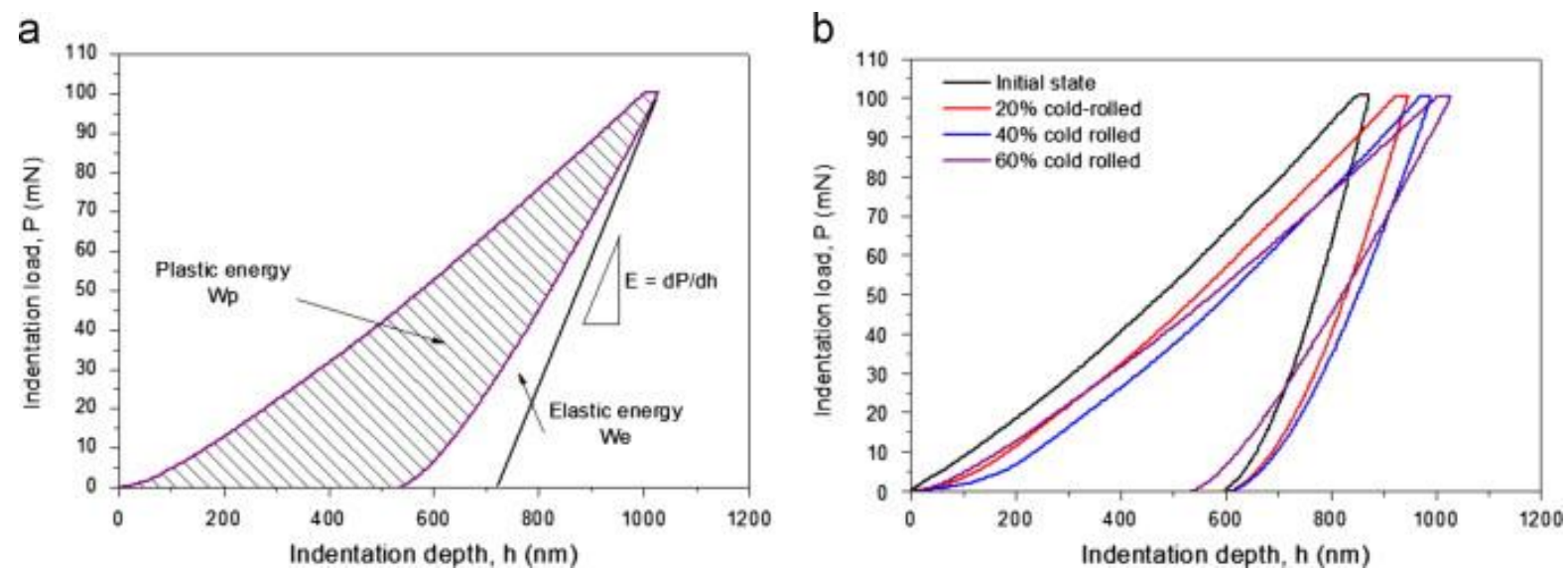

Fig. 8. Load-indentation depth curves of TM processed Ti-29Nb-9Ta-10Zr alloy; a typical aspect of a loading-unloading nanoindentation curve; $b$ - loading-unloading nanoindentation curves of TM processed alloy.

Fig. $8 \mathrm{~b}$ shows obtained load-indentation depth curves in the case of TM Ti-29Nb-9Ta-10Zr processed alloy, the initial, $20 \%, 40 \%$ and $60 \%$ cold-rolled states. In the case of a maximum load of $100 \mathrm{mN}$, it can be observed that the maximum indentation depth increases with increasing of thickness reduction. The maximum indentation depth is obtained in the case of $60 \%$ cold-rolled state. Another important observation refers to recovered depth (elastic recovery), which is increasing also with increasing of thickness reduction.

Fig. 9 shows the evolution of Instrumented Elastic Modulus (EIT) (Fig. 9a), Instrumented Hardness (HIT) (Fig. 9b) and Vickers microhardness (Fig. 9c) as a function of structural state. It can be seen from Fig. 9a that Young's modulus decreases gradually with the increase of cold-rolling reduction, from approx. $75.56 \pm 3.77 \mathrm{GPa}$, corresponding to initial state, to approx. $45.29 \pm 3.81 \mathrm{GPa}$, corresponding to $60 \%$ cold-rolling thickness reduction.
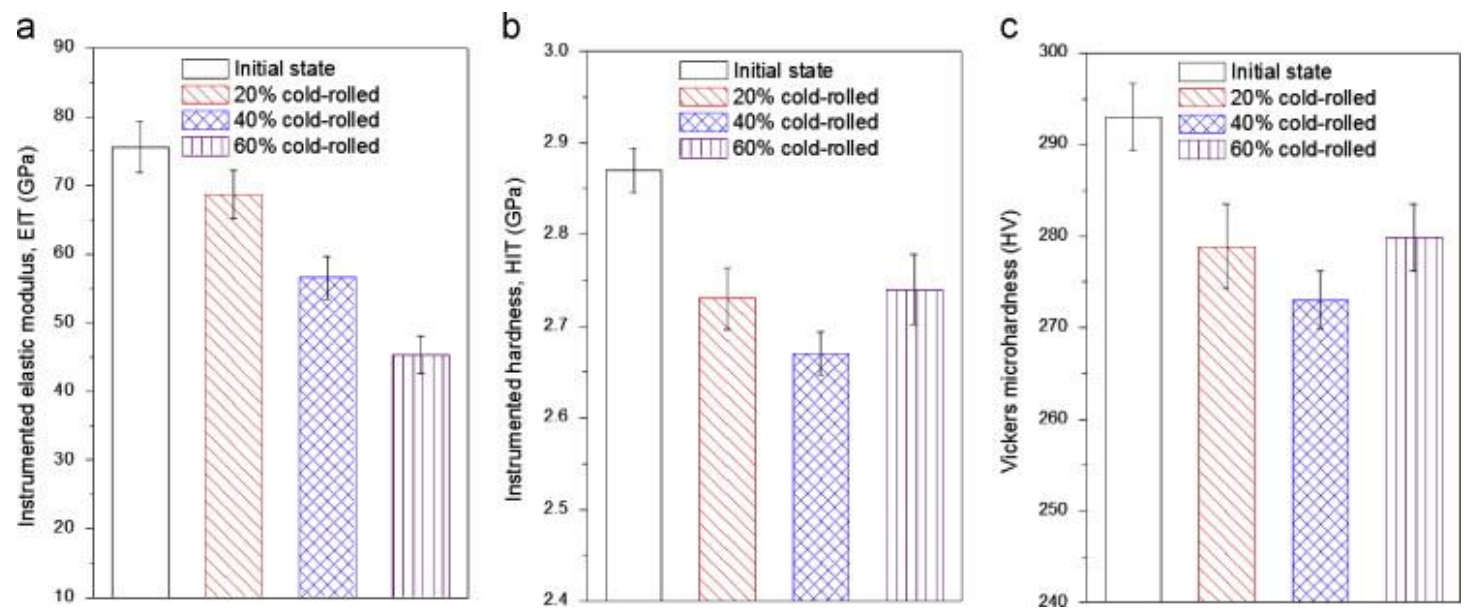

Fig. 9. Calculated nanoindentation parameters of $\mathrm{TM}$ processed $\mathrm{Ti}-29 \mathrm{Nb}-9 \mathrm{Ta}-10 \mathrm{Zr}$ alloy; a - variation of Instrumented Elastic Modulus (EIM); b - variation of Instrumented Hardness (HIT); c - variation of Vickers microhardness (HV).

In the case of multi-phase materials the material's Young modulus is mainly determined by the Young's modulus of individual phases [32] and [33]. In the case of investigated TM processed $\mathrm{Ti}-29 \mathrm{Nb}-9 \mathrm{Ta}-10 \mathrm{Zr}$ alloy, as observed from XRD investigations, the volume 
fraction of $\alpha^{\prime \prime}$-Ti phase is continuously increasing with cold-rolling reduction and the grainsize of $\alpha^{\prime \prime}$-Ti phase is continuously decreasing with cold-rolling reduction. The variation of EIT modulus can be explained mainly on increased volume fraction of stress-induced $\alpha^{\prime \prime}-\mathrm{Ti}$ phase resulted during cold-rolling. It was showed that in the case of $\beta$-Ti alloys the $\alpha^{\prime \prime}-\mathrm{Ti}$ martensite exhibits a lower Young's modulus than $\beta$-Ti phase [34] and [35]. An easy way to control the Young's modulus of a $\beta$-Ti alloy is to control the $\alpha^{\prime \prime}-\mathrm{Ti} / \beta$-Ti phase proportion, a higher $\alpha^{\prime \prime}$-Ti phase volume fraction leading to lower elastic modulus.

The elastic modulus of a phase is crystallographic dependent, showing different values according to different crystallographic directions. In the case of $\beta$-Ti phase it was showed that the elastic modulus is decreasing in the following order: [001] $\langle[110]\langle[111] \approx[112]$ [36] and [37]. As observed in Fig. 4, the most present $\beta$-Ti phase crystal directions is represented by [111], parallel to normal-direction ND (investigation direction), which shows an orientation density almost double in the case of $40 \%$ and $60 \%$ cold-rolled states in comparison with $20 \%$ cold-rolled state, suggesting an increase in elastic modulus of the $\beta$-Ti phase corresponding to $40 \%$ and $60 \%$ cold-rolled states. However, the elastic modulus is decreasing, suggesting that the influence of crystallographic anisotropy of the elastic modulus is surpassed by the increased volume fraction of $\alpha^{\prime \prime}$-Ti phase.

From Fig. 9b it can be seen that the Instrumented Hardness (HIT) also decreases gradually with the increase of cold-rolling reduction but only up to $40 \%$ cold-rolling thickness reduction, from approx. $2.87 \pm 0.23 \mathrm{GPa}$ to approx. $2.67 \pm 0.024 \mathrm{GPa}$. At $60 \%$ cold-rolling thickness reduction results an HIT increase to approx. $2.74 \pm 0.038 \mathrm{GPa}$. The HIT behaviour can be explained by taking into consideration three main factors. First, the hardness of a multi-phase material is determined by the hardness of individual phases, $\alpha^{\prime \prime}$-Ti phase exhibiting a lower hardness in comparison with $\beta$-Ti phase [35], an increase in volume fraction of $\alpha^{\prime \prime}$-Ti phase leads to a lower hardness. Second, the presence of ultrafine and nanoscale size grains, caused by cold-rolling deformation, contributes to the strengthening via the Hall-Petch relationship [38], leading to hardness increasing. Third, the presence of increasing density of dislocation networks and dislocation tangles (also playing an important role in strengthening) [17] with cold-rolling reduction progress, also leads to hardness increasing. Taking into consideration all three competitive factors, it can be assumed that up to $40 \%$ cold-rolling reduction the influence of both Hall-Petch strengthening (a higher coldrolling reduction leads to a lower grain-size) and increasing density of dislocations (a higher cold-rolling reduction leads to a higher density of dislocations) is surpassed by the influence of increased $\alpha^{\prime \prime}-\mathrm{Ti}$ volume fraction (a higher cold-rolling reduction leads to a higher $\alpha^{\prime \prime}-\mathrm{Ti}$ volume fraction), when the HIT value is reaching a minima. For a cold-rolling reduction above $40 \%$, the HIT value is increasing, the influence of both Hall-Petch strengthening and increasing density of dislocations surpassing the influence of increased $\alpha^{\prime \prime}$-Ti volume fraction.

Analyzing major texture components of $\beta$-Ti phase formed during cold-rolling can be observed that the increase of hardness (HIT), for a cold-rolled reduction above $40 \%$, coincide with volume fraction increasing of $\{111\}\langle 1 \overline{2} 1\rangle$ and $\{111\}\langle\overline{1} \overline{1} 2\rangle$ texture components, suggesting that the major influence is played by the density of dislocations (a higher energy for dislocation movement is necessary in twinning deformation in comparison with slip deformation).

A similar evolution was obtained also in the case of Vickers microhardness (Fig. 9c), showing close microhardness values in comparison with HIT values (Fig. 9b). 


\section{Conclusions}

The effects of cold-rolling deformation on the texture evolution and mechanical properties of $\mathrm{Ti}-29 \mathrm{Nb}-9 \mathrm{Ta}-10 \mathrm{Zr}$ alloy were investigated. The main results can be summarized as follows:

(1) The $\alpha^{\prime \prime}$-Ti phase increases with cold-rolling progress, at $60 \%$ cold-rolling thickness reduction the $\alpha^{\prime \prime}$-Ti phase transformation still increasing;

(2) During cold-rolling deformation the following major texture components were formed:

- at 20\% cold-rolling thickness reduction: $\gamma$-fibre components: $\{111\}\langle 1 \overline{1} 0\rangle$ and $\{111\}\langle 0 \overline{1} 1\rangle$;

- at $40 \%$ cold-rolling thickness reduction: $\gamma$-fibre components: $\{111\}\langle 1 \overline{1} 0\rangle$ and $\{111\}\langle 0 \overline{1} 1\rangle$; texture component: $\{112\}\langle\overline{1} \overline{1} 1\rangle$ and texture components: $\{001\}$ $0 \overline{1} 0\rangle$ and $\{010\}\langle 001\rangle$;

- at $60 \%$ cold-rolling thickness reduction: $\gamma$-fibre components: $\{111\}\langle 1 \overline{1} 0\rangle ;\{111\}$ $\langle 0 \overline{1} 1\rangle ;\{111\}\langle 1 \overline{2} 1\rangle$ and $\{111\}\langle\overline{1} \overline{1} 2\rangle ;$ and texture components: $\{001\}\langle 0 \overline{0} 0\rangle$ and $\{010\}\langle 001\rangle$;

(3) The Ti-29Nb-9Ta-10Zr alloy cold-rolled with $60 \%$ thickness reduction possessed a low Young's modulus, of about $45.29 \mathrm{GPa}$, coupled with an average Vickers microhardness, of about $279.83 \mathrm{HV}$, hence it has a great potential to be used in biomedical applications.

\section{Acknowledgement}

This work was supported by a grant of the Romanian National Authority for Scientific Research, CCCDI - UEFISCDI, Project no. MNT-7-075/2013.

\section{References}

[1] J. Eckert, J. Das, W. Xu, R. Theissmann, Mater. Sci. Eng. A, 493 (2008), pp. 71-78

[2] W. Xu, K.B. Kim, J. Das, M. Calin, J. Eckert, Scr. Mater., 54 (2006), pp. 1943-1948

[3] W. Xu, K.B. Kim, J. Das, M. Calin, B. Rellinghaus, J. Eckert, Appl. Phys. Lett., 89 (2006) (0319061-3)

[4] V. Brailovski, S. Prokoshkin, M. Gauthier, K. Inaekyan, S. Dubinskiy, M. Petrzhik, M. Filonov, Mater. Sci. Eng. C, 31 (2011), pp. 643-657

[5] Y.F. Xu, D.Q. Yi, H.Q. Liu, B. Wang, F.L. Yang, Mater. Sci. Eng. A, 529 (2011), pp. 326-334

[6] D. Ionita, M. Grecu, M. Dilea, V.D. Cojocaru, I. Demetrescu, Metall. Mater. Trans. B, 42 (2011), pp. 1352-1357

[7] E. Vasilescu, P. Drob, D. Raducanu, V.D. Cojocaru, I. Cinca, D. Iordachescu, R. Ion, M. Popa, J. Mater. Sci.: Mater. Med., 21 (2010), pp. 1959-1968

[8] M.V. Popa, E. Vasilescu, P. Drob, V.D. Cojocaru, C. Vasilescu, Rev. Chim. (Bucharest, Rom.), 60 (2009), pp. 29-33

[9]C.W. Lin, C.P. Ju, J.H. Chern Lin, Biomaterials, 26 (2005), pp. 2899-2907 
[10] P. Majumdar, S.B. Singh, M. Chakraborty, J. Mech. Behav. Biomed. Mater., 4 (2011), pp. 11321144

[11] L.M. Elias, S.G. Schneider, S. Schneider, H.M. Silva, F. Malvisi, Mater. Sci. Eng. A, 432 (2006), pp. $108-112$

[12] P.L. Ferrandini, F.F. Cardoso, S.A. Souza, C.R. Afonso, R. Caram, J. Alloys Compd., 433 (2007), pp. 207-210

Article

[13] L. Wang, W. Lu, J. Qin, F. Zhang, D. Zhang, J. Alloys Compd., 469 (2009), pp. 512-518

[14] J.I. Qazi, B. Marquardt, L.F. Allard, H.J. Rack, Mater. Sci. Eng. C, 25 (2005), pp. 389-397

[15] M. Niinomi, T. Akahori, S. Katsura, K. Yamauchi, M. Ogawa, Mater. Sci. Eng. C, 27 (2007), pp. 154-161

[16] Y.L. Hao, S.J. Li, S.Y. Sun, C.Y. Zheng, R. Yang, Acta Biomater., 3 (2007), pp. 277-286

[17] Y.F. Xu, D.Q. Yi, H.Q. Liu, X.Y. Wu, B. Wang, F.L. Yang, Mater. Sci. Eng. A, 547 (2012), pp. 64-71

[18] F. Bachmann, R. Hielscher, H. Schaeben, Solid State Phenom., 160 (2010), pp. 63-68

[19] F. Bachmann, R. Hielscher, P.E. Jupp, W. Pantleon, H. Schaeben, E. Wegert, J. Appl. Crystallogr., 43 (2010), pp. 1338-1355

[20] W.C. Oliver, G.M. Pharr, J. Mater. Res., 7 (1992), pp. 1564-1580

[21] W.C. Oliver, G.M. Pharr, J. Mater. Res., 19 (2004), pp. 3-20

[22] A.C. Fischer-Cripps, Surf. Coat. Technol., 200 (2006), pp. 4153-4165

[23] H.Y. Kim, T. Sasaki, K. Okutsu, J.I. Kim, T. Inamura, H. Hosada, S. Myazaki, Acta Mater., 54 (2006), pp. $423-433$

[24] V.D. Cojocaru, D. Raducanu, D.M. Gordin, I. Cinca, J. Alloys Compd., 576 (2013), pp. 170-176

[25] M. Holscher, D. Raabe, K. Lucke, Acta Metall. Mater., 42 (1994), pp. 879-886

[26] D. Raabe, K. Lucke, Mater. Sci. Technol., 9 (1993), pp. 302-312

[27] B. Sander, D. Raabe, Mat. Sci. Eng. A, 479 (2008), pp. 236-247

[28] L. Wang, W. Lu, J. Qin, F. Zhang, D. Zhang, Mater. Sci. Eng. A, 491 (2008), pp. 372-377

[29] T. Inamura, Y. Kinoshita, J.I. Kim, H.Y. Kim, H. Hosoda, K. Wakashima, S. Miyazaki, Mater. Sci. Eng. A, 438-440 (2006), pp. 865-869

[30] C. Chen, M.P. Wang, S. Wang, Y.L. Jia, R.S. Lei, F.X. Zia, B. Huo, H.C. Yu, J. Alloys Compd., 513 (2012), pp. 208-212

[31] E. Bertrand, P. Castany, I. Peron, T. Gloriant, Scr. Mater., 64 (2011), pp. 1110-1113 
[32] Z.Y. Fan, Scr. Metall. Mater., 29 (1993), pp. 1427-1432

[33] Y.L. Hao, M. Niinomi, D. Kuroda, K. Fukunaga, Y.L. Zhou, R. Yang, A. Suzuki, Metall. Mater. Trans. A, 33 (2002), pp. 3137-3144

[34] H. Matsumoto, S. Watanabe, S. Hanada, J. Alloys Compd., 439 (2007), pp. 146-155

[35] L. Wang, W. Lu, J. Qin, F. Zhang, D. Zhang, Mater. Sci. Eng. A, 490 (2008), pp. 421-426

[36] M.Y. Gutkin, T. Ishizaki, S. Kuramoto, I.A. Ovid'ko, Acta Mater., 54 (2006), pp. 2489-2499

[37] T. Inamura, H. Hosoda, K. Wakashima, S. Miyazaki, Mater. Trans., 46 (2005), pp. 1597-1603

[38] O. Ertorer, T. Topping, Y. Li, W. Moss, E.J. Lavernia, Scr. Mater., 60 (2009), pp. 586-589 